\title{
Orientation's Role in Addressing the Developmental Stages of Parents
}

\author{
Bonita C. Jacobs and Elizabeth A. With
}

\begin{abstract}
Parents of traditional-age students confront many developmental challenges of their own when their children begin college. Yet, few parent orientation programs address these challenges during the orientation process. The current study was designed to determine how well two sessions that addressed the parents' developmental changes were evaluated compared to more traditional orientation activities. The two sessions were highly evaluated as parents cited these programs as two of the three most beneficial and named the speakers as the most helpful in orientation.
\end{abstract}

Orientation professionals have long sought ways in which they can influence the retention and graduation rates of students. They have found that a comprehensive parent orientation program can be an extremely effective way to influence the collegiate experience for traditional-aged students (Sandeen, 2000). Displaying concern for parents during orientation can underscore a campus belief that parents are partners in the educational process of students. The attitudes demonstrated during orientation "send subtle but powerful messages . . . about what and who is valued (and not valued) on a campus" (Pascarella \& Terenzini, 1991, p. 650).

Research has indicated that the more supported a student feels, by the family as well as the institution, the more successful that student is likely to be (Cabrera, Nora, Terenzini, Pascarella, \& Hagedorn, 1999). Parental interest and support of their sons and daughters can directly influence the degree of satisfaction students have with college (Hatch, 2000). Also, parental beliefs can shape student expectations of college (Turrentine, Schnure, Ostroth, \& Ward-Roof, 2000).

Parents can affect the first year experience of the student and a well-informedparent can reinforce the importance of campus resources to the student (Mann, 1998;

Mullendore \& Hatch, 2000). Thus, for parents to be able to assist their students, colleges must provide them with valuable information about their campuses. This information might include the academic support services offered, academic requirements (including advising and registration), housing and dining options and rules, safety and security issues, and financial aid. Gaining support from the parents and giving them a wealth of information about the campus is only part of the responsibility of a successful parent orientation program. Even helping parents understand the emotional development of entering students is incomplete coverage in the orientation agenda. Orientation directors must also help parents to understand their own developmental issues as their students leave for college.

Most student development professionals are well-versed in the developmental tasks facing our traditional-age students ... As

Bonita C. Jacobs, Ph.D., is the Vice President for Student Development and Elizabeth A. With is the Assistant Vice President for Student Development, both at the University of North Texas in Denton, Texas. 
orientation professionals, we may be less familiar with the developmental tasks facing the parents of our students but for anyone programming with this population, this knowledge is crucial. Many parent orientation programs over the years have been built on the foundation of educating parents about the changes inherent in the passage from late adolescence to early adulthood but have ignored the parents' own issues (except in terms of the adolescent). Knowing that the separation process is a mutual one, we do half the job if we view the process solely through the adolescent lens. (Austin, 1993, p. 100)

Orientation is more than a program or workshop; it is the beginning of a process of separation for the entire family. As such, the process must communicate to parents that each student has the potential to be successful in college, that parental support is vital to that success, and that the college or university cares about students and wants them to be successful (Tederman, 1997). Institutions can also take this opportunity to help parents understand about the 'first year experience for parents' including some of the issues that they are likely to face during this transitional period.

For example, it is important for orientation presenters to discuss with parents the 'empty nest/den syndrome;' the importance in discussing concerns with the other parent; the new adult-to-adult relationships with their sons and daughters; and how to continue to provide open communication, support, and understanding during the transitional adjustments (Johnson \& Schelhas-Miller, 2000; Levine \& Cureton, 1998). Mullendore (1998) further suggested that "students (and parents) need to understand that parents, too, may change during this time" (p. 57).

\section{Research Procedures}

\section{Research Question}

The current study was designed to determine how well two sessions, designed to address the developmental changes parents might encounter as their students enter college, were evaluated compared to the other traditional orientation activities. These two programs were implemented in the parent orientation program at a large metropolitan campus of 28,000 students in the southwest.

\section{Participants}

The participants of the study were 593 parents who attended parent orientation during summer 2000 and who completed the overall conference evaluation form. Since 1,306 parents attended orientation, 713 did not complete the evaluation form and were thus not a part of the study. Thus, $45 \%$ of the parents participated in the study.

\section{Procedures for the Collection of Data}

The orientation program consisted of six, three-day sessions held during the 
summer. All parents who were in attendance on the final day of orientation at each of the six sessions were given the evaluation at breakfast on the third day. Incentives, such as t-shirts, were provided to the parents throughout the orientation program to entice them to participate in events, and were also used as incentives to get parents to fill out the evaluation forms.

\section{Instrument}

The instrument measured overall perceptions of the parent orientation program as well as of specific interest sessions. The research-developed instrument asked participants to evaluate all facets of the orientation program through a 26 item questionnaire. Twenty-three of the items utilized a Likert-type scale with ranges from 1-to-5, with 1=low rating (poor) and 5=high rating (good). The final three items called for an open-ended response by asking the participants to name the parts of the program that were most beneficial, what needed improvement, and the names of individuals who were most helpful during the orientation process.

\section{Data Analysis}

Percentage distributions were used to rate the effectiveness of the parent orientation program. Responses given to the open-ended items were examined and determinations were made as to whether the statements were positive or negative. The number of positive and negative comments was calculated for all facets of the program.

For the purpose of the study, the two sessions that discussed the developmental aspects of parents were evaluated in comparison with other sessions. Specifically, the Likert-type scale responses and the individual comments about the sessions and/or the presenters were compared to orientation sessions that did not address the developmental needs of the parents.

The first of two sessions addressing the developmental changes of parents were presented on the first day of the three-day parent orientation program. The presenter was the director of the learning center who discussed various changes she experienced as her students entered and graduated college. She purposefully mixed amusing anecdotes with traumatic experiences for both the students and the parents during the transitional college years. She identified transitional issues specific to parents, particularly those of separation, helplessness, new familial dynamics as well as new parent-adult relationships. As a trained counselor, the speaker had an assuring demeanor and was considered one of the premier presenters on campus.

The second session was an after-lunch speech on the second day of orientation. The presentation was given by the vice president for student development who announced at the beginning of the discussion that she would be talking about the freshman year for parents. She explained that they too experienced a number of changes as their students enter college. She used anecdotes from Letting Go: A Parent's Guide to Understanding the College Years (Coburn \& Treeger, 1997) as a reference point and included extensive humorous personal references as an administrator and a parent. Parents reported feeling 
a great deal of emotion during the presentation as the presenter discussed the students leaving and the experiences the parents might face.

\section{Results}

The two sessions with ratings on the Likert-type scale of 4.205 and 4.106 were higher than both the median of 4.045 and the mean of 4.051 for all sessions in orientation. The scores were higher than more traditional orientation events such as open houses, tours, and the activities mart, and sessions on advising and commuting.

The two sessions were cited as beneficial more often than all except the academic dean's session. Thus, the parents considered these two programs more beneficial to them than other more traditional sessions. Neither of these two sessions were as one that needed improvement. In addition, the two speakers were cited as the most helpful in orientation more often than any other presenter with the exception of the orientation directors. Parents felt the presenters were helpful to them and that they benefited from their presentations.

\section{Discussion and Limitations}

As the evaluation was administered on campus during the last morning, parents who did not attend the breakfast did not have an opportunity to provide input. As a side note, the breakfast was not well attended nor well evaluated, and thus places real limitations on the study findings. The initial, exploratory nature of the data, however, is powerful in initiating a critical conversation about the importance of parental orientations.

The halo effect (Saunders \& Cooper, 2001); i.e., rating the presenters based upon their overall impression with orientation, is also a possible concern with the study. Orientation was evaluated strongly, and some parents may have rated the presenters higher based upon their overall impressions with orientation. As a result, a longitudinal approach to data collection along with the collection of qualitative data may prove helpful in further advancing the conversation about parent orientation.

The evaluation tool did not ask whether the two sessions benefited the participants specifically in their understanding of the developmental transitions of parents when their sons and daughters leave for college. Perhaps the data on these sessions would have been enhanced had the questions been more precisely worded to ask about participants' post-session understanding of parent developmental issues.

The results, however, were consistent with anecdotal information gained through conversations with parents during orientation. Parents expressed they had a greater level of confidence and were more prepared for their students leaving for college. They particularly cited appreciation for the discussions about their mixed emotions as their students left for college. In particular, the speakers' acknowledgement that there is both excitement surrounding the students entering college and sadness about primary parenting years coming to an end resonated with the parents.

Clearly valuing parents and discussing their developmental changes with them during orientation can be helpful. This can also be helpful for the institution and for the 
successful transition of students. Parents who have an understanding of their own developmental changes would be presumably better equipped to assist students in their own transitions. In addition, the positive responses from parents in this study indicated that these issues are well-received by parents, the result of which is an increased level of support to the institution.

\section{References}

Austin, D. M. (1993). Orientation activities for the families of new students. In M. L. Upcraft, R. H. Mullendore, B. O. Barefoot, \& D. S. Fidler (Eds.) Designing successful transitions: A guide for orienting students to college (pp. 97-109). Columbia, SC: The National Resource Center for the Freshman Year Experience.

Cabrera, A., Nora, A., Terenzini, P., Pascarella, E., \& Hagedorn, L. (1999). Campus racial climate and the adjustment of students to college: A comparison between white students and African-American students. Journal of Higher Education, 70(2), 134-150.

Coburn, K. L., \& Treeger, M. L. (1997). Letting go: A parent's guide to understanding the college years. New York, NY: Harper Collins.

Hatch, C. (2000). Parent and family orientation. In M. J. Fabich (Ed.), Orientation planning manual (pp. 39-44). Pullman, WA: National Orientation Directors Association.

Johnson, H. E., \& Schelhas-Miller, C. S. (2000). Don't tell me what to do, just send money: The essential parenting guide to the college years. New York, NY: St. Martin's Press.

Levine, A., \& Cureton, J. (1998). When hope and fear collide: A portrait of today's college student. San Francisco: Jossey-Bass.

Mann, B. A. (1998). Retention principles for new student orientation programs. The Journal of College Orientation and Transition, 6(1), 15-26.

Mullendore, R. H. (1998). Including parents and families in the orientation process. In R. H. Mullendore (Ed.), Orientation Planning Manual, (pp. 56-62). Bloomington, IN: National Orientation Directors Association.

Mullendore, R. H., \& Hatch, C. (2000). Helping your first-year college student to succeed: A guide for parents. Columbia, SC: National Resource Center for the First-Year Experience and Students in Transition.

Pascarella, E., \& Terenzini, P. (1991). How college affects students. San Francisco: Jossey-Bass.

Sandeen, C. A. (2000). Developing effective campus and community relationships. In M. J. Barr, M. K. Desler, and Associates (Eds.), The handbook of student affairs administration, (pp. 377-392). San Francisco: Jossey-Bass.

Saunders, S. A., \& Cooper, D. L. (2001). Programmatic interventions: Translating theory to practice. In R. B. Winston, Jr., D. G. Creamer, T. K. Miller, and Associates (Eds.), The professional student affairs administrator, (pp. 309-340). 
Tederman, J. S. (1997). Advice from the dean. Washington, DC: National Association of Student Personnel Administrators, Inc.

Turrentine, C. G., Schnure, S. L., Ostroth, D. D., and Ward-Roof, J. A. (2000). The parent project: What parents want from the college experience. NASPA Journal, 38(1), 31-43. 